\title{
A NOVEL REGIONAL-RESIDUAL SEPARATION APPROACH FOR GRAVITY DATA THROUGH CRUSTAL MODELING
}

\author{
Nelson Ribeiro Filho ${ }^{1}$, Cristiano Mendel Martins² and Renata de Sena Santos 3,4
}

\begin{abstract}
Gravity anomalies normally contain information of all sources beneath Earth's surface. Once residual anomalies exhibit information about the main target, the knowledge of this specific residual signal is extremely important to interpretation. To find this signal, it's necessary to perform regional-residual separation. We present here a new approach of separation by using gravity crustal modeling. We divide the surface in prisms, with density given by GEMMA. We calculate the regional signal, assuming Earth's crust can be the source of observed anomaly. This methodology was applied on Barreirinhas basin-Brazil. Its formation is related to geologic events in South America-Africa break. Besides, the complex geology is the main obstacle on finding the residual anomaly. We compare our methodology with robust-polynomial fitting and spectral analysis. They were not able to identify the residual anomaly. Main trouble relies on absence of crust information. Those kind of environment usually requires forward modeling and/or gravity inversion. On the other hand, our approach considers all crust's parameters. Then the difficulty on choosing the residual no longer exists. The residual anomaly follows a geologic pattern. The crustal depocenter was mapped between structural faults. Therefore, our results satisfies the main expectation and are extremely linked to Barreirinhas basin's geological background. We recommend this separation procedure, once Earth's crustal model and gravity data are available for all planet.
\end{abstract}

Keywords: gravity modeling, GEMMA model, Barreirinhas basin, residual anomaly.

RESUMO. Anomalias gravimétricas contêm informações de todas as fontes na superfície terrestre. Uma vez que anomalias residuais exibem informações sobre alvos principais, o conhecimento desse específico sinal residual é extremamente importante para interpretação. Para encontrá-lo, é necessário realizar separação regional-residual. Apresentamos aqui uma nova abordagem de separação utilizando a modelagem gravimétrica crustal. Discretizamos a superfície em prismas, com densidade fornecida pelo modelo GEMMA. Calculamos o sinal regional, assumindo que a crosta terrestre é a fonte da anomalia observada. Aplicamos esta metodologia na bacia de Barreirinhas - Brasil, que tem sua formação relacionada aos eventos geológicos de separação da América do Sul e África. Além disso, a complexidade geológica é considerada o principal obstáculo para encontrar esta anomalia residual. Comparamos nossa metodologia com Ajuste Polinomial Robusto e Análise Espectral. Essas técnicas não foram capazes de identificar a anomalia residual. 0 principal problema se dá pela ausência de informações acerca da crosta. Para esse ambiente, geralmente requer modelagem direta e/ou inversão geofísica. Por outro lado, nossa abordagem considera todos os parâmetros crustais e a dificuldade em escolher o residual deixa de existir. A anomalia residual apresenta um padrão geológico. 0 depocentro crustal foi mapeado entre falhas estruturais. Nossos resultados satisfazem a expectativa principal e estão extremamente ligados ao cenário geológico da bacia. Recomendamos este procedimento de separação, uma vez que os modelos crustais e dados gravimétricos estão disponíveis para todo o planeta.

Palavras-chave: modelagem gravimétrica, modelo GEMMA, bacia de Barreirinhas, anomalia residual.

\footnotetext{
${ }^{1}$ Observatório Nacional - ON/MCTI, Rio de Janeiro, Brazil - E-mail: nelsondelimar@gmail.com

2Universidade Federal do Pará - UFPA. Belém, PA, Brazil -E-mail: mendelmartins@gmail.com

3Universidade Federal do Oeste do Pará - UFOPA. Santarém, PA, Brazil - E-mail: res.santos87@gmail.com

${ }^{4}$ Programa de Pós-Graduação em Geofísica - UFPA.
} 


\section{INTRODUCTION}

Gravity signal is a composition of all nearby sources beneath Earth's surface that are resulted from the superposition of gravitational masses effect, since shallow minerals and components from deep crustal structures (Telford et al., 1990; Blakely, 1996). This signal usually has two aspects: a more positive component which is due to large features; and a more negative signal that is a response of isolated sources or geological faults for example. Gravity anomaly is presumed to be negative as usual, because density contrast between sediment's layers and crustal basement is negative. Despite that, there is another possible source of influence that can strongly change the observed signal, such as the crust-mantle surface (Moho). That fact causes significant changes in amplitude of the signal and it also makes the gravity interpretation dependent on separating the existing different signals.

Regional-residual separation is extremely essential in gravity and magnetic data interpretation. It allows the interpreter on identifying local and minor signals that normally correspond a specific targets, like mineral sources and oil-gas reservoir that are usually hidden. Besides, it is not a easy task to perform, once there many factors that must been considerate, such as the location of potential anomaly, its geologic information and, in the gravity study-case, the type of anomaly that separation will be applied on. Those regional-residual application have been improved for the past few years and a variety of techniques were proposed by several authors.

The first group of authors analyses the signal spectrum through wavenumber domain, by dividing anomalies in those with short and others with large wavelength (Spector \& Grant, 1970). However, this technique will only work if either the low frequency part of the spectrum is linear or an identifiable break in the energy spectrum occurs, which is not often the case. Spectral analysis was used in order to separate those signals in many study cases (Gupta \& Ramani, 1980; Jacobsen, 1987; Pawlowski \& Hansen, 1990; Pawlowski, 1995; Ridsdill-Smith, 1998; Keating \& Pinet, 2011; Tenzer et al., 2012). A second group has been used wavelet transform to perform this separation (Fedi \& Quarta, 1998). That specific technique was first introduced in the last decades and it has been applied due to its good property of multi-scale analysis at different depths. This main quality provides a more comfortable way on identifying regional anomalies Some important researches by using wavelet transform are presented in (Yang et al., 2001; Sailhac \& Gibert, 2003; Xu et al., 2009). A third group does that separation by searching for polynomials that fit the behavior of gravity anomaly, once it is assumed that the regional field can be approximated by a low-order polynomial up to 3 degree (Beltrão et al., 1991). It tries modeling the total gravity field and not to the unknown regional field. Due to this fact, any attempt of modeling a complex regional by a high-degree polynomial order is sensitive to the noise transmission (Beltrão, 1989). Furthermore, the final residual anomaly that is obtained after fitting polynomial data is presented only positive or negative, but never both. This technique has also been used for several authors: Guspí \& Introcaso (2000); Martín et al. (2011); Martínez-Moreno et al. (2015); Montesinos et al. (1999). In addition to, the main difficult of polynomial fitting relies on the presence of complex geologic area, where faults or lineament features still be contributing in gravity signal even after the regional data is fitted.

An additional possibility to obtain information about the regional gravity contribution is incorporate the crustal modeling. The main purpose is to remove its effects from the observed data and select the true residual signal. In addition, one path to perform it is assuming that depth of crust is known. This depth can be acquired from several existing studies for estimating crust depth. Many researchers have developed new Earth crustal models through different approaches: Bagherbandi \& Eshagh (2012); Eshagh et al. $(2016,2017)$ have used vertical gravity-gradient data; Woo Kim et al. (2000); Leftwich et al. (2005); von Frese et al. (1999) applied correlation between free-air and terrain gravity anomalies; and Barzaghi et al. (2015); Uieda \& Barbosa (2016); Assumpção et al. (2013); Van der Meijde et al. (2013) presented crustal model from spherical approximation along with gravity and seismic data as well.

Most of regional-residual separation studies in existing literature do not involve an approach by using estimated crustal model. It usually does not consider neither the geologic events that have formed the environment nor the geometric parameters of the lithosphere that are involved. Moreover, all achievements in satellite missions have provided an exceptional improvement on using gravity data for modeling, inversion and interpretation, by having great reliability. Therefore, this reality motivated us to present a new procedure of regional-residual separation that is based on crustal modeling.

In this paper, we have used the crust model of Moho relief, density distribution and geological province from GEMMA (GOCE Exploitation for Moho Modeling and Application), proposed by (Sampietro et al., 2013; Reguzzoni \& Sampietro, 2015; Sampietro, 2016). This specific crustal model was obtained 
through a compilation of grounded, marine and satellite gravity data from GOCE mission (Rebhan et al., 2000; Drinkwater et al., 2006; Migliaccio et al., 2010; Floberghagen et al., 2011) and seismic tomography as well. We also selected simple Bouguer anomaly from GOCE satelite mission, which is available in ICGEM/GFZ-Postdam platform (Drewes et al., 2016). Despite the choice of this specific gravity anomaly provides very interesting result, a important discuss must be done: we are not restraining the modeling procedure and this new approach of regional-residual separation on to this kind of gravity data. He have used Bouguer anomaly because the main cause of a gravity anomaly in a sedimentary basin occurs due to the density contrast between sediments and basement. Nevertheless, it is also possible perform this by using gravity disturbance or free-air anomaly.

Our selected study area is Barreirinhas basin, located in northeast Brazil. Its formation is associated with different geologic and tectonic events that were related to the opening of South Atlantic ocean. Those events also succeeded the separation between South American and African during the Cretaceous. The separation was performed by using crustal modeling. In order to compare with other strategies, we also have applied robust polynomial fitting and spectral analysis. In addition to, the comparison between those techniques shows big differences in amplitude and shape of residual anomaly as well as the regional signal. Therefore, our approach has proved efficiency and it should be used for all kind of gravity studies.

\section{A BRIEF REVIEW OF ROBUST POLYNOMIAL FITTING AND SPECTRAL ANALYSIS \\ Robust polynomial fitting}

An adjustment method definition usually has two dependencies: an specific objective function and a criteria decision. In the least squares method $(L S)$, for example, the objective function is defined by the sum of differences squares between observed value and the fitted value at each sampled point; the employed decision criterion is the minimization of objective function. An estimator $M$ can be obtained by minimizing the objective function $Q(c)$ :

$$
Q(c)=\sum_{i=1}^{N} u\left(\frac{r_{i}}{s}\right)
$$

where $u$ is a robust method definition, $s$ the scale factor and $R_{i}$ the $i$-th observation residue, which is defined by the difference between observed data $\mathbf{g}$ and the new value of the function $\mathbf{f}$ :

$$
\mathbf{r}_{i}=\mathbf{g}_{i}^{0}-\mathbf{f}\left(x_{i}, y_{i}, z_{i}, c\right) .
$$

The term $\mathbf{g}_{i}^{0}$ in Eq. (2) is the $i$-th observation, $f(x, y, z, c)$ is the function's value that is going to be fitted at the $i$-th point $\left(x_{i}, y_{i}, z_{i}, c\right)$ and $C$ is the set of parameters that define the function F.

Thereby, Beltrão et al. (1991) proposed a new technique that fits a polynomial surface by using a robust procedure instead of $L S$ strategy. Then, $L S$-method can be seen as an estimator $M$ with function described as:

$$
u(v)=v^{2} .
$$

Once is considered that the regional field component can be approximated by a $\mathrm{N}$-order polynomial defined in the horizontal coordinates $x$ and $y$, the new function $\mathbf{f}$ can be written by:

$$
\mathbf{f}(x, y, z, c)=P_{n}(x, y, c),
$$

where $C$ represents the set of polynomial coefficients $P_{n}(x, y, c)$.

Polynomial fitting by $L S$ is done by considering not only the regional component but the total field. It also assumes that regional field behavior can be approximated by a polynomial of degree 1, 2 or 3-degree. In spite of that, polynomial with larger degrees can provide residual components with smaller amplitude (Beltrão, 1989). In order to avoid the larger degree-problems, it should be used a more robust adjustment that uses a function $u(v)$ that increases slowly than $v^{2}$.

The $(k+1)$-th approximation of $c$ is obtained by:

$$
c^{(k+1)}=\left[\mathbf{A}^{T} \mathbf{W}^{(k)} \mathbf{A}\right]^{-1} \mathbf{A}^{T} \mathbf{W}^{(k)} \mathbf{g}^{0},
$$

where $\mathbf{W}$ is the $N$-dimensional diagonal weighting matrix whose elements depends implicitly on $c$, but defined in order to reduce the amplitude distortion; $\mathbf{A}$ is the $N \times M$ matrix whose elements are given by the derivative of $P_{n}$ relative to each $c_{j}$ coefficient:

$$
a_{i j}=\frac{\partial P_{n}\left(x_{i}, y_{i}, c\right)}{\partial c_{j}} .
$$

This method reduce the residual influence in the fitted regional field data by assuming that isolated anomalies are locally either positive or negative, but not both. Once the observed signal is fitted, the residual anomaly can be obtained by subtracting the regional anomaly from the observed signal.

\section{Spectral analysis}

Spectral analysis is a very useful tool that is used to separate the different components in observed signal. It consists in signal transformation by using Fourier transform from space to wavenumber domain, with purpose of identify corresponding wavelength signals and source of interference as well (Spector 


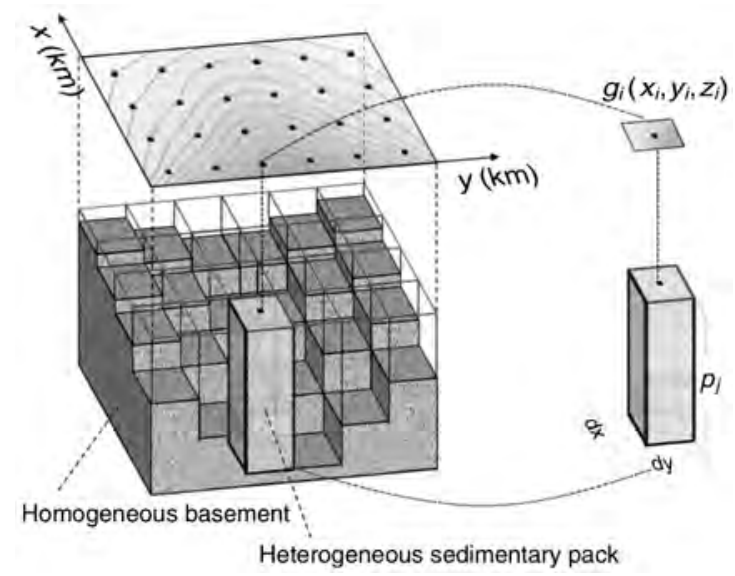

(a)

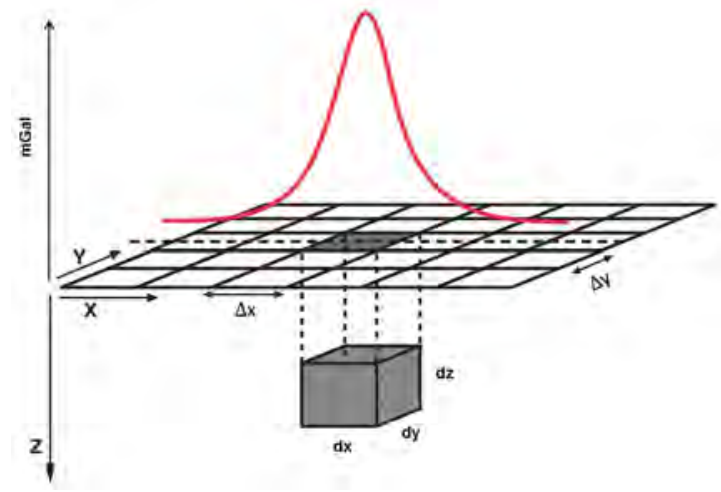

(b)

Figure 1 - (a) Illustrative model for the modeling by using a set of $M$ prisms with dimensions ( $d x, d y, d z)$. The horizontal and vertical axes are used in metric coordinates. The black dots above indicate all $N$ points of observation. In each $i$-th point, the gravity contribution of a singular $j$-th prism is calculated. Then the procedure is repeated for all set of prisms. This image model was taken from Martins et al. (2010). (b) Example of a gravity signal (red line) due to a rectangular prism taken from (a), that is displayed in a $x-y$ plan, with $z$-axis positive downward and also a positive value of density contrast.

\& Grant, 1970). In the gravity anomaly, it consists in a fast method but less subjective, once the separation occurs through filtering processes, such as low or high-pass filters and upward continuation, for example. Although both regional and residual components spectra superposition do not always provides an effective separation, it allows us to evaluate the energy spectrum of each signal component.

Spector \& Grant (1970) have studied the relationship between energy spectrum of anomalies and average source bodies depth under a statistic hypothesis. It provided a very important foundation for anomaly source parameter estimation and designation of separation filter (Dolmaz et al., 2005). The energy spectrum of anomalies can be presented by:

$$
\langle E(k)\rangle=4 \pi \mu^{2}\left\langle e^{-2 h k}\right\rangle\left\langle 1-e^{-t k}\right\rangle\left\langle S^{2}(k)\right\rangle,
$$

where \langle\rangle stands for ensemble average; $\mu$ is the density distribution/unit volume; $H$ is the source top depth, $t$ the source thickness, $k$ is the radial wavenumber, $S(k)$ is the factor for the horizontal size of the source body. It was found that the depth factor $\left\langle e^{-2 h k}\right\rangle$ dominates the spectrum, the effect of the extension factor $\left\langle 1-e^{-t k}\right\rangle$ and th of order Ne horizontal factor $\left\langle S^{2} k\right\rangle$ is comparatively small, especially in low-frequency bands. The energy spectrum can be simplified in two equations:

$$
E(r) \approx A e^{-2 h k},
$$

and

$$
\ln (E(r)) \approx-2 \bar{h} k+A^{\prime}
$$

where $A$ and $A^{\prime}$ are constant coefficients, $h^{\prime}$ is the average depth of the source body. In practice and also for convenience, the linear fitting results of different spectrum segments are plotted on the semi-log plot of energy-spectrum versus radial wavenumber. The best-fit straight line inclination of this specif plot can indicate the average depth of the sources.

\section{METHODOLOGY: GRAVITY CRUSTAL MODELING}

Let us assume a heterogeneous crust with density $\rho_{c}$ partially imposed over a homogeneous mantle with density $\rho_{m}$, which $\Delta \rho$ represents the difference between mantle and crustal densities. First of all, we delimited a finite region $R$ on the horizontal Cartesian plane $x-y$ that contains the crustal corresponded region. Those horizontal dimensions are not precisely equal. Which means that East and North coordinates do not have necessarily the same number of points. This region $R$ has a specif volume $V_{R}$ that is related to the topography and basement of the region. This volume that was selected by the crustal thickness between top and bottom of each existing layer, defined here by $z_{t}$ and $z_{b}$, with $z$-axis positive downward.

Afterward, we partitioned this volume in $M$ rectangular elementary prisms, and $M=m_{x} \times m_{y}$ is described as the number of prisms in $x$ and $y$-axis. Each prism is displayed in both horizontal and vertical directions until all crust thickness is fully filled. The dimension of each prism in horizontal and vertical directions $(d x, d y, d z)$ are known. We assume the density contrast between crust and mantle for each elementary prism is 
also known. The density is homogeneous and constant inside of each prism. However, it can vary from each prism in both lateral and vertically. Figure 1 exhibits an interpretative model with the set os prisms that is used in this methodology and its respective contribution for a prism with positive density contrast.

Thereby, let $\mathbf{g}_{z_{i}}$ be the calculated vertical gravity component that is evaluated at the $i$-th observation point $P_{i}=\left(x_{i}, y_{i}, z_{i}\right)$. In Figure $1, \mathbf{g}_{\mathbf{z}_{i}}$ is represented by $\mathbf{g}_{\mathbf{i}}$. This signal is produced by each $j$-th rectangular prism that contains a value of density $\rho$ as constant. Each prism also has a known dimensions and is located at the point $Q_{j}=\left(x_{j}, y_{j}, z_{j}\right)$. The calculation of $\mathbf{g}_{\mathbf{z}_{i}}$ was described by Nagy (1966); Blakely (1996) and can be written as:

$$
\mathbf{g}_{z_{i}}(x, y, z)=\gamma \rho \int_{x_{1}}^{x_{2}} \int_{y_{1}}^{y_{2}} \int_{z_{1}}^{z_{2}} \frac{\left(z-z^{\prime}\right) d x^{\prime} d y^{\prime} d z^{\prime}}{\left[\left(x-x^{\prime}\right)^{2}+\left(y-y^{\prime}\right)^{2}+\left(z-z^{\prime}\right)^{2}\right]^{\frac{3}{2}}},
$$

where $\gamma$ is the universal gravitational constant $(\gamma=$ $\left.6.673^{-11} \mathrm{~m}^{3} \mathrm{~kg}^{-1} \mathrm{~s}^{-1}\right) ; x, y$ and $z$ are the differences between $i$-th observation point and $j$-th prism position. The parameters $x_{1}, x_{2}, y_{1}$ and $y_{2}$ are the horizontal center of each prism and are written as $x_{1}=x-\frac{d x}{2}, x_{2}=x+\frac{d x}{2}, y_{1}=y-\frac{d y}{2}, y_{2}=y+\frac{d y}{2}$. The central depths are calculated by $z_{1}=z-\frac{d z}{2}$ and $z_{2}=z+\frac{d z}{2}$; and $\left(x^{\prime}, y^{\prime}, z^{\prime}\right)$ represent the infinitesimal prism center with volume $d v^{\prime}$, once $d v^{\prime}=d x^{\prime} d y^{\prime} d z^{\prime}$.

In order to evaluate the vertical gravity attraction of each $M$ prism, we calculate the sum of all $j$-th contributions $\mathbf{G}_{\mathbf{z} i}$, which is given by:

$$
\mathbf{G}_{\mathbf{z} i}(d x, d y, d z)=\sum_{j=1}^{M} \mathbf{g}_{z i}\left(x_{j}, y_{j}, z_{j}\right),
$$

with $j=1, \ldots, M$. Moreover, the numerical solution of Eq. (10) was presented by Plouff (1976) as:

$$
\begin{gathered}
\mathbf{G}_{\mathbf{z} i}\left(x_{i}, y_{i}, z_{i}\right)=\gamma \Delta \rho_{j} \sum_{k=1}^{2} \sum_{l=1}^{2} \sum_{m=1}^{2} \mu_{k l m} \\
{\left[z_{m} \arctan \frac{x_{k} y_{l}}{z_{m} R_{k l m}}-\right.} \\
\left.x_{k} \log \left(R_{k l m}+y_{l}\right)-y_{k} \log \left(R_{k l m}+x_{l}\right)\right]
\end{gathered}
$$

where $R_{k l m}=\sqrt{x_{k}^{2}+y_{l}^{2}+z_{m}^{2}} ; \mu_{k l m}=(-1)^{k}(-1)^{l}(-1)^{m}$; the pairs $\left(x_{1}, x_{2}\right)$ and $\left(y_{1}, y_{2}\right)$ are the some of Eq. (10); $z_{1}=z t_{j}$ and $z_{2}=z b_{j}$ represent the top and bottom of each $j$-th prism at point $Q_{j}$. The index $i, j$ and $k$ goes from 1 to 2 , which takes the final point (index with value 2 ) and initial point (index with value 1) of the difference between the observation point and the coordinates of the prism for each $x, y$ and $z$ dimensions. Equation
(12) represents the main developed numerical solution of Eq. (10).

The depths of top and bottom are provided by GEMMA crustal model (Sampietro et al., 2013; Reguzzoni \& Sampietro, 2015). It also provides the density distribution $\Delta \rho$. In addition, each value of $\Delta \rho$ is a ssociated to a possible geological provinces on surface of the Earth. Those available provinces are index from 1 to 8, listed as: oceanic crust, sedimentary basins, igneous provinces, orogenetic crust, shields, platforms, extended crust and oceanic ridges. Thereafter, next step consists in evaluating the gravity signal using both geometric and density parameters provided by the GEMMA model. This signal contains the gravity vertical attraction of: $(i)$ all heterogeneous crust's basement $\mathbf{G}_{\mathbf{z} \text { crust }} ;$ (ii) the sediment's layers displayed above basement $\mathbf{G}_{\mathbf{z} s e d}$; and (iii) the correction due to the water existing sheets below sea level $\mathbf{G}_{\mathbf{z} \text { water }}$. The final gravity signal is written by:

$$
\mathbf{G}_{\mathbf{z}}=\mathbf{G}_{\mathbf{z} \text { crust }}+\mathbf{G}_{\mathbf{z} \text { sed }}+\mathbf{G}_{\mathbf{z} \text { water }} \text {. }
$$

The final calculated gravity anomaly referred in Eq. (13) represents the regional signal. Once it was used all crust's parameters, this signal must have a behavior according to lithosphere arrangement. It also must shows all tendencies as well as the changes on geologic environment. Moreover, we evaluated the difference between observed gravity signal and the regional anomaly. It provides the residual gravity anomaly, which is related to the sedimentary basin.

It is very important to accentuate that the number of prism in both horizontal directions affects the computational cost. Usually the discretization of topography is smaller than the crust. The horizontal dimensions of each prism above crust is small when it compared with the horizontal dimension of each prism that belongs to the crust. This approach is used because of the continental and oceanic crust are more smooth than both layers of sediments and the topography. Moreover, we have chose 5 $\mathrm{km}$ of horizontal dimension. Although this specific dimension of each prism has produced a number of 10744 prism in our computation, the selected area is relatively large, and that has allowed us to choose this specific dimension. Furthermore, a biggest area requires a number of prism greater than we have used.

\section{BARREIRINHAS BASIN}

The study area corresponds to the continental part of Barreirinhas basin. This specific basin is included in the new petroleum frontier basin group. It is located at the Brazilian equatorial margin in both continental and marine part. The origin and 
evolution of Barreirinhas basin is associated to the South American and African separation. Its geology has been studied by several authors for in the last two decades (Milani et al., 2007; Trosdtorf Jr et al., 2007; Soares Júnior et al., 2008; Almeida-Filho et al., 2009; Soares Júnior et al., 2011). Those researchers define the Barreirinhas basin's limits by: Tutóia high separates it from Ceará basin; Rosário high is the limit with São Luís basin; and Ferrer-Urbano Santos arch is the limit with Grajaú basin. The location is presented in Figure 2. The contour of both South America continent and the Barreirinhas basin was taken from the CPRM Database (CPRM, 2014), such as the geological information.

\section{Geological settings}

The opening of South Atlantic ocean has been dominated by extension and transform movement. Those motions are associated with the giant equatorial fracture zones. Due to that, our specif area is one of the best places in the world to seek distinctive features of continental margin graben associated with transform rather than spreading movement (Burke, 1976). In addition to, Brazilian Equatorial Margin (define here as BEM) was formed by extension and strike-slip displacement. Those movements were related to rifting and early opening of the South Atlantic Ocean as well. This process resulted in several coastal sedimentary basins (Almeida-Filho et al., 2009).

Barreirinhas basin, for example, was formed after several geologic events that have occurred in the Neotriassic that resulted on South American-African separation. Continental fragmentation and Atlantic formation occurred along with lots of others sedimentary basis at Brazilian equatorial margin. Some of those basins can be highlighted, such as Foz do Amazonas and Pará-Maranhão basins (Trosdtorf Jr et al., 2007; Soares Júnior et al., 2008).

The complex tectonic evolution of those sedimentary basins still warrants additional data to discuss further the significance of fault's reactivation during the later stages of their geologic history (Almeida-Filho et al., 2009). Barreirinhas basin, forms a deep graben system. Those geologic features are limited by normal faults with NW-SE orientation and located over igneous and metamorphic rocks of the São Luís Craton. This set of characteristics suggests that our study area was deeply affected by tectonics, presenting channels that were established along the mentioned structural faults (De Matos, 2000).

Almeida-Filho et al. (2009) presented a study by using cross information between digital elevation model surface produced by Shuttle Radar Topographic Mission (SRTM) and geophysical data. The purpose of this study was to demonstrate of the high influence of lineaments at the area and also possible tectonic reactivation along passive margins. The author also describes the existence of a large sedimentary pile. This set of layers reaches $1600 \mathrm{~m}$ of thickness and it occurs over the Sobradinho platform, and it is also described in De Matos (2000). A geological map allows us to view the existence of a complex features as well as the basin's main depocenter (see Fig. 3). This significant component of the basin is located over the Sobradinho's fault block, which accommodates the thickest Mesozoic-Cenozoic sedimentary piles along all Brazilian marginal basins, with more than 10 km (Feijó, 1994; Almeida-Filho et al., 2009).

Krueger (2012) developed a important research based on gravity and seismic data. In this work, profiles of seismic reflection across Barreirinhas basin revealed deep-water folds and belts. Those structures are linked to the extensional fault system. Beyond that, gravity data mapped thrust faults that was interpreted as results of a shortening that was caused by extension activities. Moreover, gradient of free-air anomaly highlights many tectonic features, including the continental margin, Ceará Rise, zones of fracture and the seamount (Krueger et al., 2012).

The most important characteristic of Barreirinhas basin is the abrupt transition zone between oceanic and continental crust. It is a result of being located on a transform margin, consequently with a very narrow and steep continental inclination. Therefore, due to this characteristic, usually free-air anomaly map shows a two continuous lobes-sequence. This unusual signature represents the effect that is produced due to the crust geometric arrangement (Allen \& Allen, 2013). In another words, the crust top with abrupt relief and the bottom more smooth corresponds to both lack and mass excess. It is associated with a more flexible Moho relief instead of a abrupt compensation that produces this kind of signal in free-air anomaly map (Watts, 2001).

\section{Observed gravity anomalies}

Free-air anomaly map shows a two continuous lobes-sequence that represents a specfic type of signature that is produced by crust geometric arrangement Allen \& Allen (2013). Its minimum and maximum amplitudes are equal to -92 and $116 \mathrm{mGal}$, respectively. As main particulars, negative values are associated to the two described basins: São Luís and Barreirinhas. Most positive value is continuous and represents the transition crustal zone. Furthermore, simple Bouguer anomaly is prevailing 


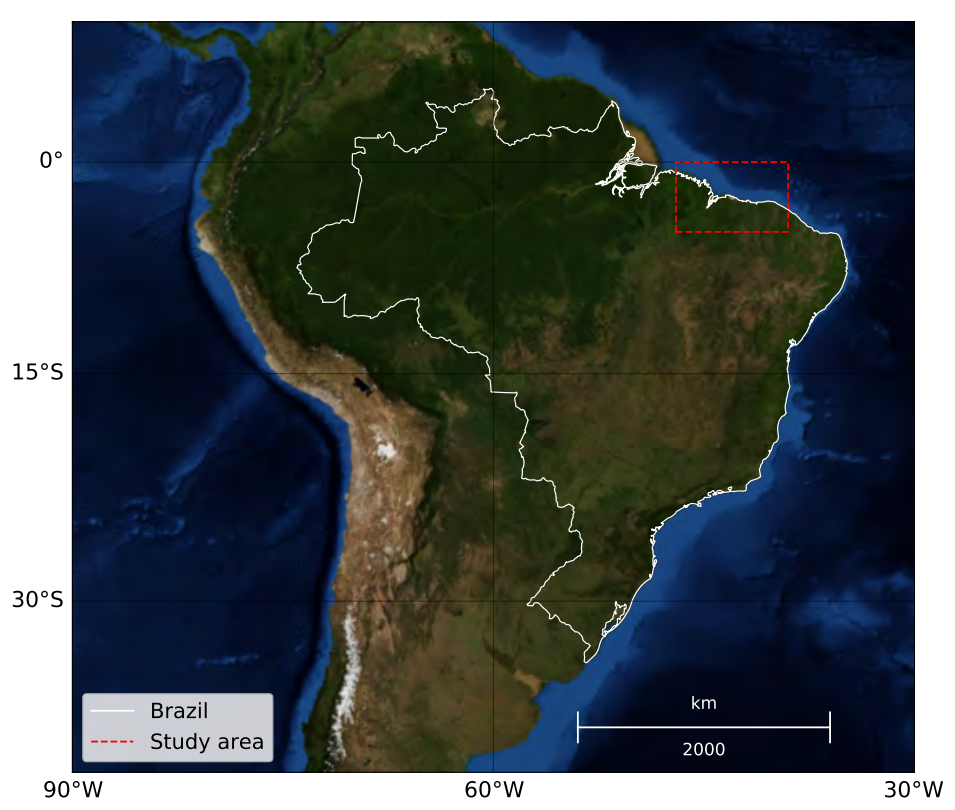

(a)

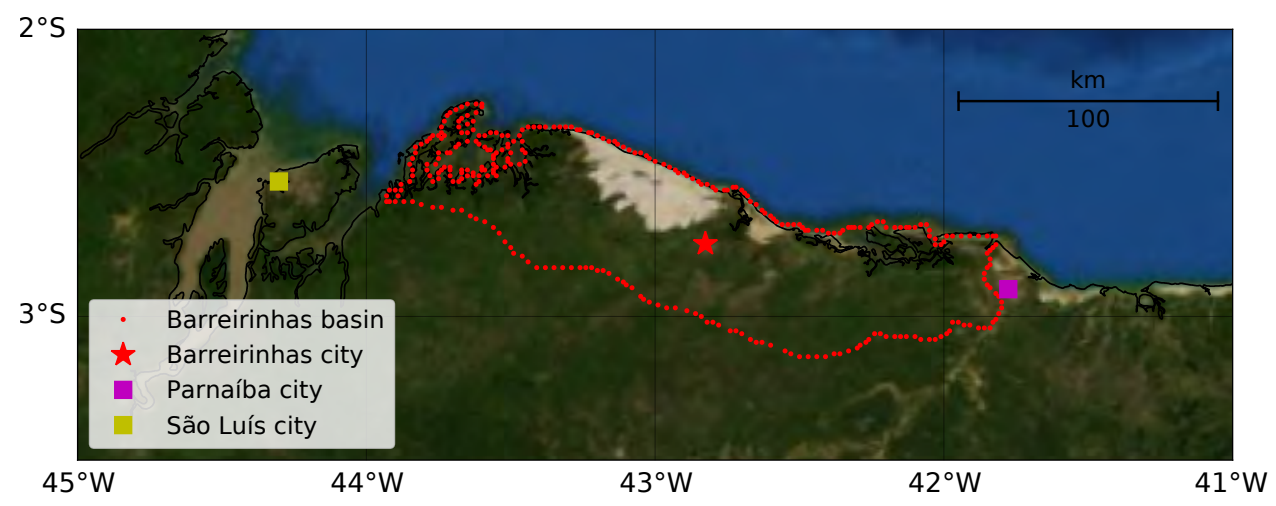

(b)

Figure 2 - (a) Map of South America continent. The white contour represents the geographic limits of Brazil and the red dashed-line indicates our specific study area, which is Barreirinhas basin. (b) Location map of our selected study area, located at Brazilian continental margin (Maranhão state, Northeast region). The red dots indicate the onshore part of Barreirinhas basin; this specific contour of this basin was drew with a shapefile that was taken from CPRM Database.

negative over continental and ocean-transition zones as well. It is also completely positive in North-east direction. Likewise free-air anomaly map, negative values in Bouguer anomaly along continent are related to São Luís and Barreirinhas basins. In the meanwhile, positive values show the transition zone slightly smaller in amplitude than the free-air anomaly. Both anomalies are shown in Figure 4.

It is very important to point out that we selected an area of gravity data that is bigger than our specific Barreirinhas basin's area. The reason we did this is that we must have this difference, in order to avoid complications on the edges and also another computational effects or errors that can come out.

\section{RESULTS}

Here we present all result that were obtained by using each technique for regional-residual separation as well as the resulted found from te developed methodology by applying gravity crustal modeling with $3 \mathrm{D}$ rectangular prisms. 


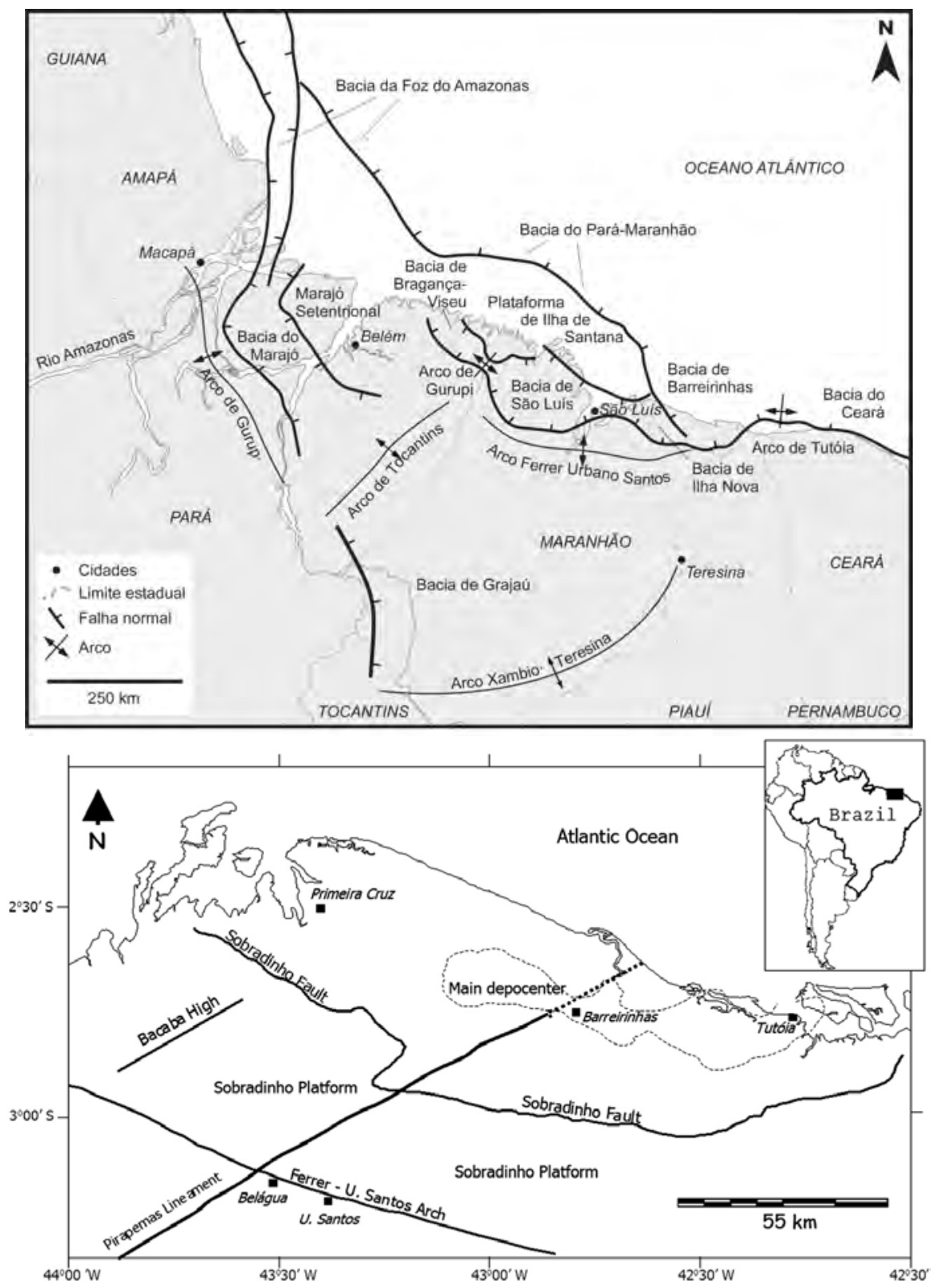

Figure 3 - (a) Simple geologic map that exhibits the existing arches, faults and geologic highs at Barreirinhas basin that were formed during the separation between African and South America. There is also possible reactivated normal and reversal faults. Reference: Soares Júnior et al. (2008). (b) Geologic map that was taken from Almeida-Filho et al. (2009). It shows the main tectonic lineaments along the terrestrial part of Brazilian's northeast. The main depocenter of the crustal part of Barreirinhas basin is show around $43^{\circ}$ of longitude as well.

\section{Spectral analysis}

We have applied Spectral Analysis technique by using filtering in a sequence procedure. First we chose a band-pass filter in order to reduce the noise content by removing the spectrum of high frequencies from the signal. Most of $3 \mathrm{~km}$ short-wavelength were removed. Afterward, we correctly applied gravity separation. The procedure was finished when both signals indicated coherency of best approximation-approach. The regional assumed as Moho relief signal and residual presumed for basin contour. Both gravity signals are shown in Figure 5. 


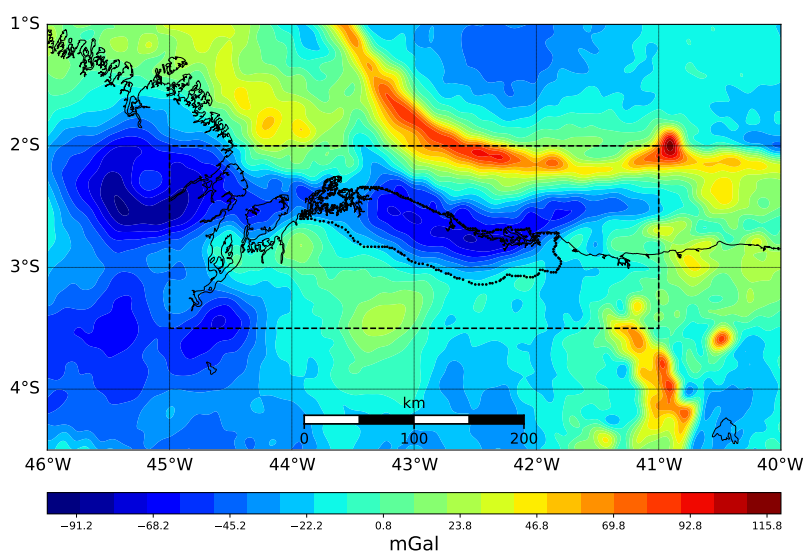

(a)

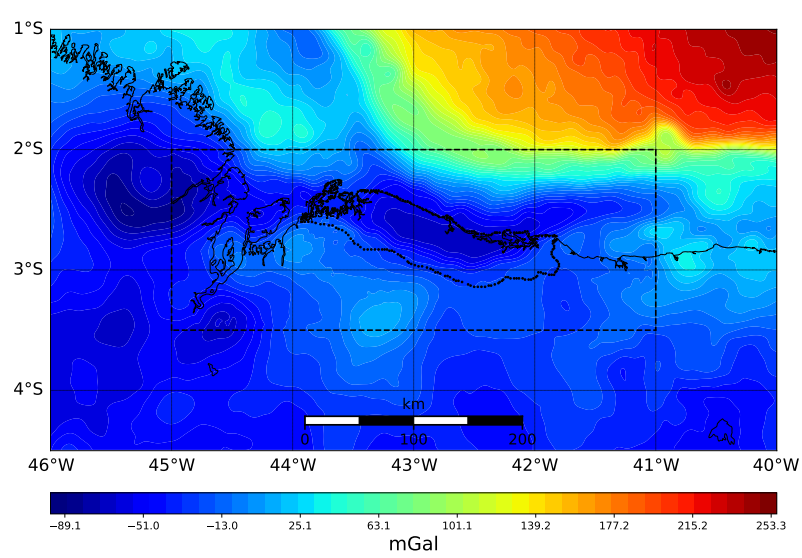

(b)

Figure 4 - (a) Free-air anomaly map of Barreirinhas basin. Amplitudes are -92 and 116 mGal. (b) Simple Bouguer anomaly map of Barreirinhas basin. Amplitudes are -90 and $254 \mathrm{mGal}$. Black continuous-line represents the coast line; the black box indicates the specific study area; and the black dashed-lines represent Barreirinhas basin contour in continental part. Both data were taken from ICGEM website; the grid space is $0.5^{\circ} \times 0.5^{\circ}$ in latitude and longitude.

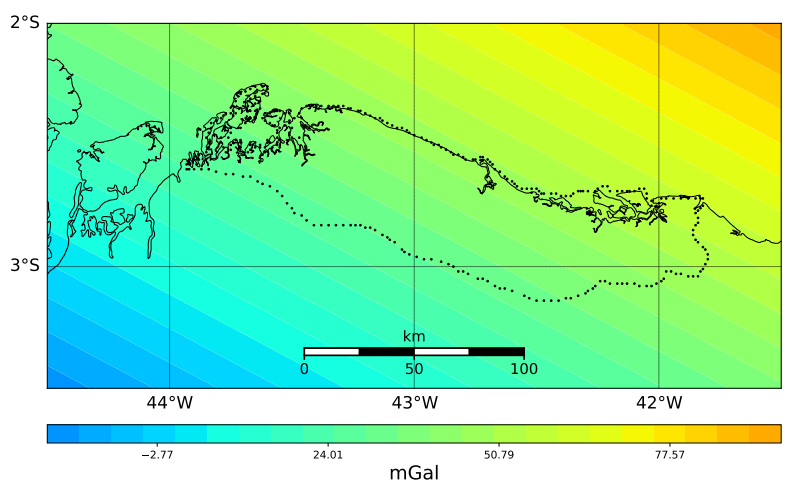

(a)

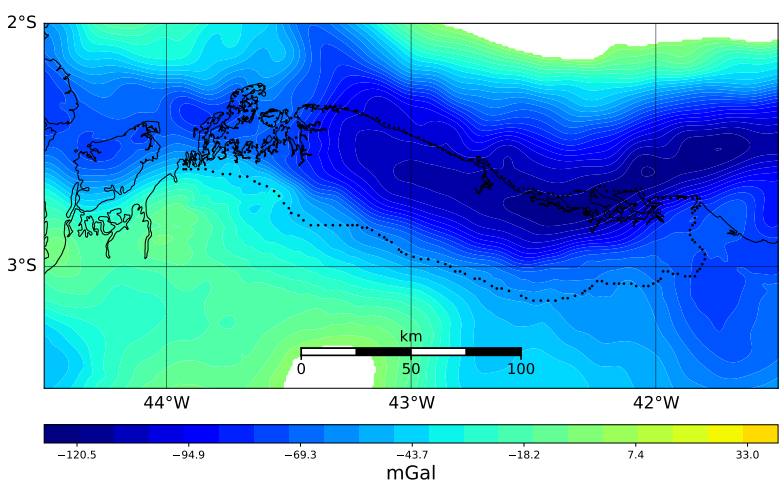

(b)

Figure 5 - (a) Regional and (b) residual Bouguer anomaly map obtained from spectral analysis. Regional has amplitude from -83.5 to 158 mGal, while residual map ranges from -121 to $110 \mathrm{mGal}$. Black continuous line is the coast line and black dashed line indicates Barreirinhas basin contour of crustal part.

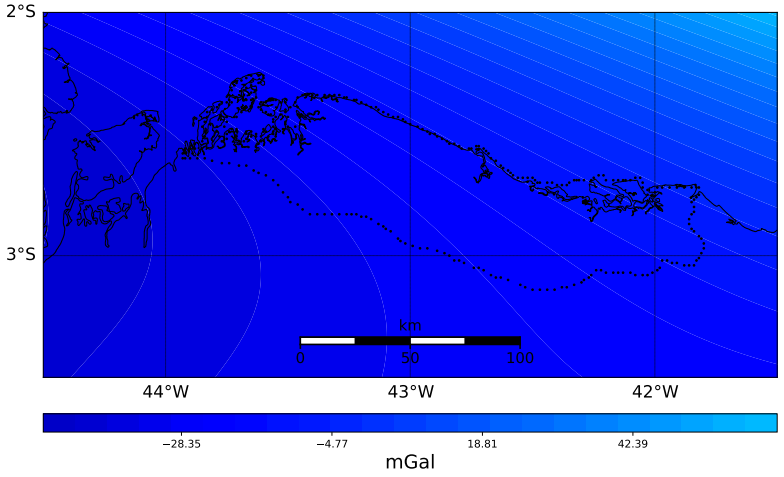

(a)

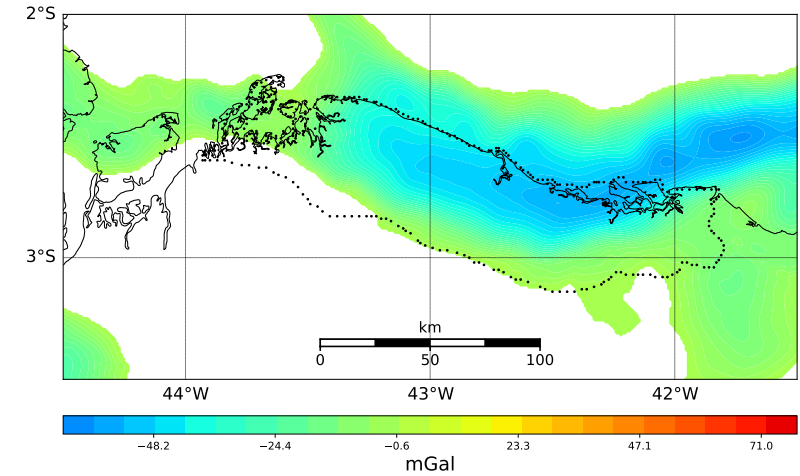

(b)

Figure 6 - (a) Regional and (b) residual Bouguer anomaly map obtained by fitting a $3^{\text {rd }}$-degree polynomial. Regional has amplitude from -76 to 350 mGal, while residual map ranges from -120 to 95 mGal. Black continuous line is the coast line and black dashed line indicates Barreirinhas basin contour of crustal part. 
Regional signal shows itself as a complete NE-tendency. It clearly was not able to indicate large geologic structures and Moho relief signal as well. Lower gravity values in residual anomaly can be mistaken with faults and geologic features contributions and are all located near to platform-transition zone. Moreover, those values delineated the residual gravity anomaly, but are not confined in Barreirinhas basin.

\section{Robust polynomial fitting}

The results of robust polynomial fitting were performed by using from 1 to 6 degree. In comparison with the results presented in spectral analysis section, we selected all solutions based on same established criteria, which is regional gravity anomaly following Moho surface and residual caused by sedimentary basin. Polynomials of 3, 4 and 6 degrees have shown solutions closer to a tolerable result.

Third and fourth-degree polynomials exhibited a more similar regional signal in comparison to spectral analysis (see Fig. 5) even though gravity anomaly along continent shows lower negative values in robust fitting technique. Furthermore, both solutions were not closed to residual anomaly obtained from spectral analysis. This fact indicates that they also were not able to delimited the sedimentary basin's edges. Those results are displayed in Figures 6 and 7.

Sixth-degree polynomial presented a regional signal with amplitude lower than other solutions. Both lower negative values and the high positive tendency in NE-direction followed free-air and Bouguer anomaly maps (see Fig. 4). Besides, residual signal shows large transition zone-influence that was shown in regional anomaly. This result is presented in Figure 8.

It is possible to note that all most lowers gravity values located close to platform-transition zone are outlining in residual gravity anomaly. That includes a simple expectation of a signal due to a sedimentary basin. However, there is not any geologic feature whose gravity anomaly causes a function with large degree. That is why the specific residual can be considered as a pseudo-anomaly. Moreover, the existing crustal depocenter would cause one single low gravity value, but not two, which does appear in this result. Despite that, the $6^{\text {th }}$-degree polynomial was clearly the best solution between all three presented.

\section{Crustal modeling}

Regional-residual separation through crustal modeling was performed by calculating the regional gravity signal due to $M$ rectangular prism with horizontal dimensions equal to $d x=$ $d y=5 \mathrm{~km}$. The top and bottom of each prism was selected by assuming the values of crustal depth. The density contrast were chosen by using information about geological province. In our specific case, we have used oceanic crust, platforms and extend crust to calculate the full gravity contribution. However, only extend crust is contained in the main crustal part of Barreirinhas basin. In addition, for each province there is an associated density value that slowly decrease in the means that depth is bigger. Thus, all values are related to continental-oceanic crust and existing sediment layers. GEMMA's parameters of top and bottom of the crust are displayed in Figure 9.

The gravity vertical attraction due to the set of prisms was calculated by using density contrast. It means that each value of $\rho$ was subtracted from the Bouguer density in continental part (i.e. $\rho_{\text {crust }}=2.673 \mathrm{~g} / \mathrm{cm}^{3}$ ). In marine zone, the specific density value was set by GEMMA as well, which is equal to the water density (i.e. $\rho_{w}=1.03 \mathrm{~g} / \mathrm{cm}^{3}$ ). By doing that, we were able to assume that this signal corresponds to regional anomaly. Likewise, the residual signal was computed by subtracting the observed gravity signal and the crust contribution due to the $M$ prisms. The final result is shown in Figure 10.

It can be seen on residual map presented in Figure 10 that the developed modeling procedure is delimiting the sedimentary basin's contour more effectively. Those limits were not found in the results from spectral analysis (see Fig. 5) or robust polynomial fitting (see Figs. 6, 7 and 8). Additionally, it is possible to establish three important assertions: (i) residual gravity anomaly is confined by the mapped structural faults; (ii) shape of the anomaly is associated with fault positions and existing lineaments; and (iii) the basin's deepest region in continental zone is located extremely close to the main crustal depocenter. Furthermore, this depocenter was already mapped in Almeida-Filho et al. (2009). Figure 11 shows the residual gravity anomaly map over a simple structural and tectonic map as a following background.

This great result shown in Figure 11 illustrates the existing correlation between the map of residual gravity anomaly and all structural faults that were mapped until now. The main reason that guarantee our affirmation is the main depocenter location, which is similar to a few studies in existing literature. Further, it is extremely possible to affirm that there might be other faults and geologic features as well that were not described yet. Once the contour of residual anomaly follows a specific tendency, a reasonable explanation would be the association with all possible geologic structures. 


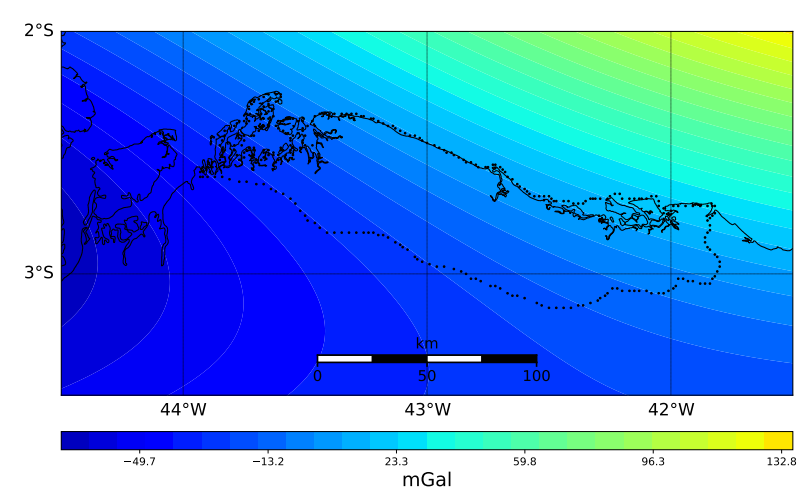

(a)

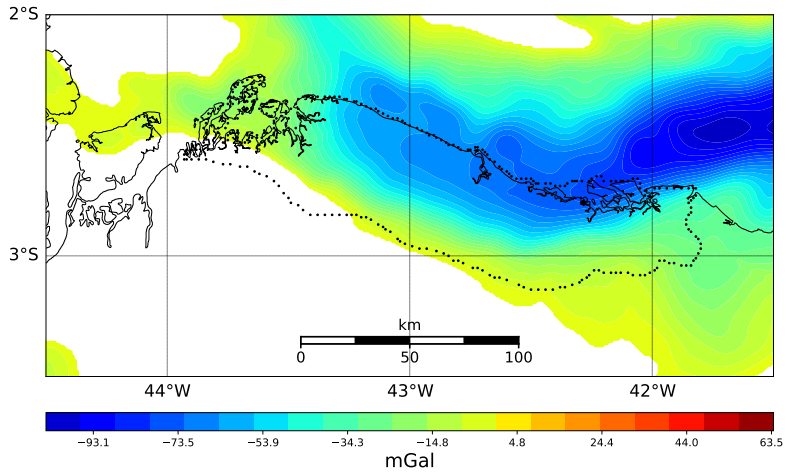

(b)

Figure 7 - (a) Regional and (b) residual Bouguer anomaly map obtained by fitting a $4^{\text {th }}$-degree polynomial. Regional has amplitude from -87 to $243 \mathrm{mGal}$, while residual map ranges from -113 to 64 mGal. Black continuous line is the coast line and black dashed line indicates Barreirinhas basin contour of crustal part.

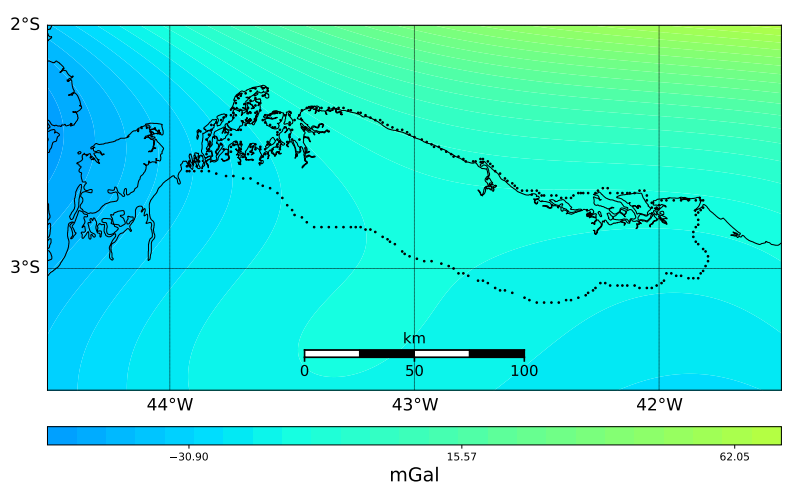

(a)

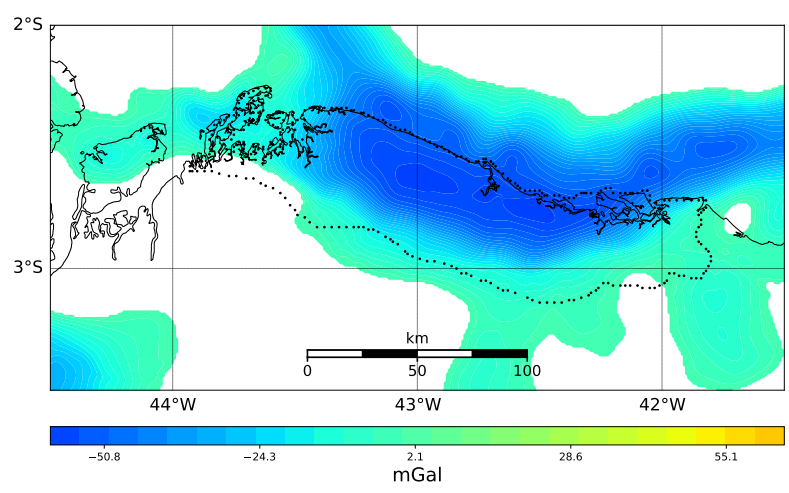

(b)

Figure 8 - (a) Regional and (b) residual Bouguer anomaly map obtained from fitting a $6^{\text {th }}$-degree polynomial. Regional has amplitude from -171 to $248 \mathrm{mGal}$, while residual map ranges from -104 to $133 \mathrm{mGal}$. Black continuous line is the coast line and black dashed line indicates Barreirinhas basin contour of crustal part.

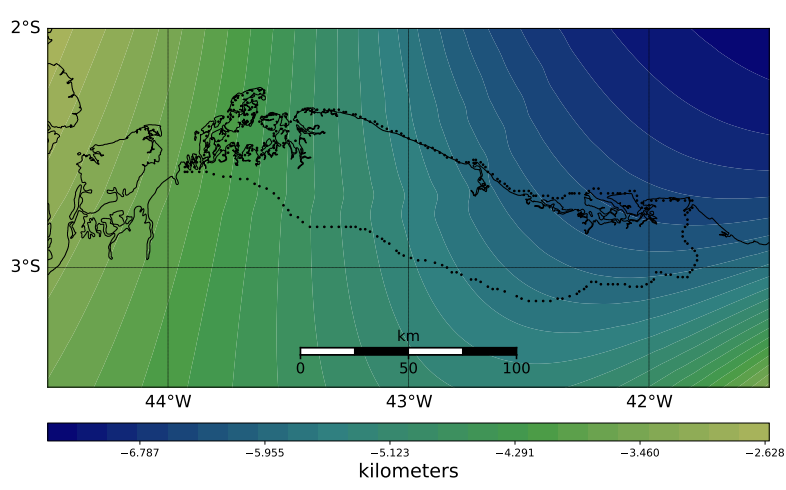

(a)

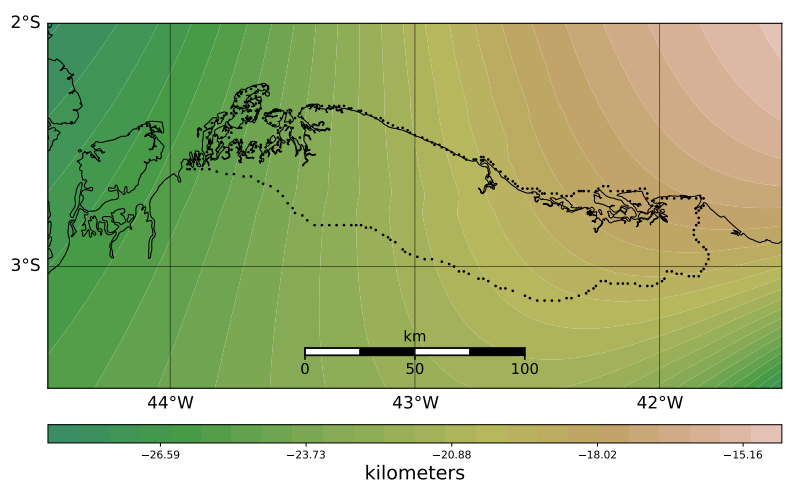

(b)

Figure 9 - Depths of (a) crust top and (b) crust bottom that were obtained from GEMMA Earth crustal model. All measures are in km and the contours lines are in 2.5 $\mathrm{km}$. In this specific case, the depth are displayed as negative just to indicate all values below a mean sea level. Depth of crust top ranges from $300 \mathrm{~m}$ to $7.6 \mathrm{~km}$ and bottom goes from 12 to $38 \mathrm{~km}$. 


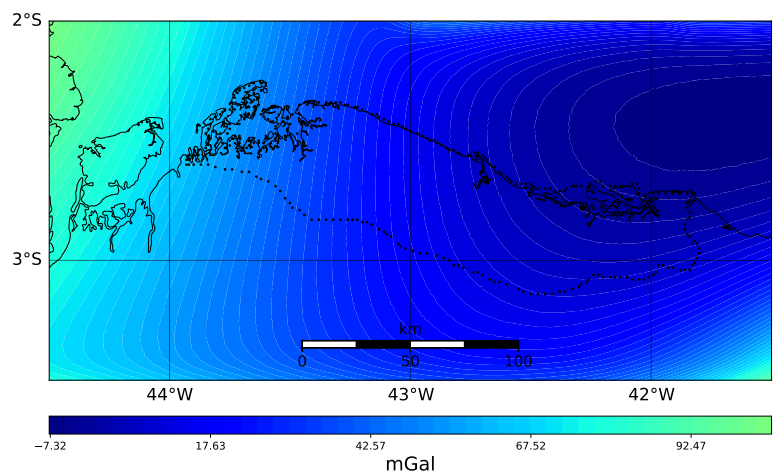

(a)

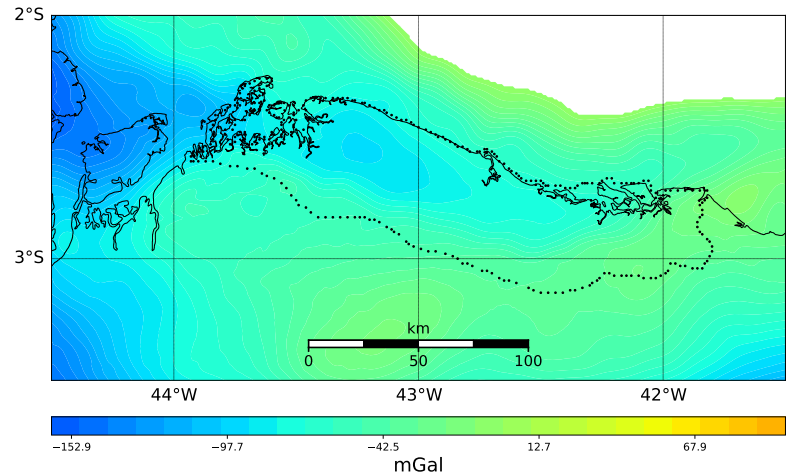

(b)

Figure 10 - (a) Regional and (b) residual Bouguer anomaly map obtained from crustal modeling. Regional has amplitude from -7.5 to 102 mGal, while residual map ranges from -159 to 0 mGal. Black continuous line is the coast line and black dashed line indicates Barreirinhas basin contour of crustal part.

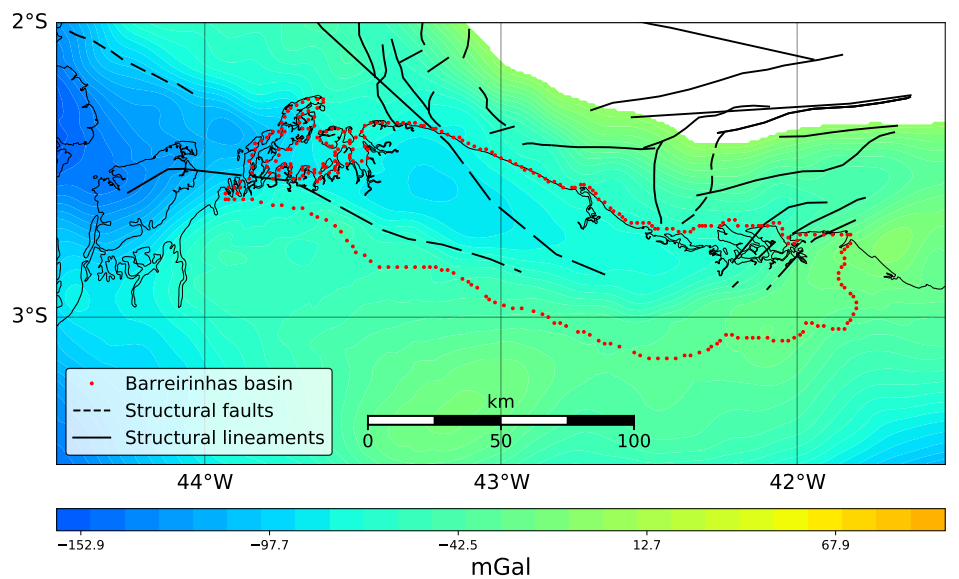

Figure 11 - Final residual gravity anomaly map of Barreirinhas basin. Black continuous lines represent structural and tectonic lineaments while dashed lines are indicating geologic faults. The coast line is still in a black continuous line, however thinner than the others. All faults position and dimension were taken from CPRM Cartographic Database (CPRM, 2014). As result, the deepest zone inside continental part along Barreirinhas basin contour (red dots) is referring to the main crustal depocenter.

\section{MAIN DISCUSSION}

Although spectral analysis and robust polynomial fitting techniques are said to be effective, both were not able to mark the limits of continental part of the basin. Those techniques have failed due to the fact that Moho relief surface is an intense source, usually assumed as large part of regional signal or all of it. The main difficulty with these tested methods relies on crust geometric arrangement in that area. The spectrum of wavenumber is not able to identify the abrupt change in Moho surface. Two acceptable interpretation would be: (i) the identification of this abrupt geometry as a small feature that causes great distortion in the signal or (ii) a large-deep crustal structure that is responsible for masking the signal providing by the sedimentary basin. In addition, all coefficients in robust polynomial fitting would not be able to fit the true regional gravity signal, no matter the degree we choose. Continental-equatorial margin has a complex geologic context, where Moho can mask the residual data. Also, abrupt changes in the crust and its depth are significant sources in gravity anomalies as well.

Nevertheless, the residual map obtained through crustal modeling sketched more effectively the contour of Barreirinhas basin. This residual signal shows mapped and unmapped faults in 
the area. On top of that, Moho's gravity signal is very different and it has a West-East variation instead of North-South. Due to that, the best performance on selecting residual signal from crustal modeling it is straightforward. It shows how important is having geological knowledge in any study area. Therefore, there are essential information about crustal parameters, such as top and bottom depth, and densities as well. As a consequence of that, the identification of residual signal become easier and more reliable through crustal modeling, rather than other regional-residual separation techniques already outdated.

\section{CONCLUSIONS}

Selecting the best residual gravity anomaly is a tough task for both geologist and geophysicist, since there are many techniques to apply and several possible results to obtain. In order to achieve a more significant result, we developed a approach of regional-residual separation by using crustal modeling. We selected as study area the continental part of Barreirinhas basin, that has not only a geological environment but also a deep-large thickness package of sediments. With the purpose of validate our methodology, we also have applied regional-residual separation by using spectral analysis and robust polynomial fitting. Those techniques were not effective on mark the boundaries of the basin in residual anomaly though. It occurred because Mohorovicic surface appears as a intense source of interference, which was formerly discussed. In addition, crust's geometry produces a two-lobes effect in free-air anomaly with one negative and other positive. This signature disappears in Bouguer anomaly and also can be a valuable information that is hidden.

The regional-residual separation by using crustal modeling was shown to be more efficient on selecting the residual gravity anomaly, once all crust geometric attributes are present in GEMMA model. Moho regional signal is associated to crust position and geometry. Besides, it also has different orientation when compared to the regional signal obtained from other techniques. The corresponding basin's anomaly is constrained by structural faults. Variations in the shape are associated to the position of geologic features and the deepest area inside continental zone represents the main crustal depocenter. The main difficulty on applying regional-residual separation rests on the geometric shape of the crust in this specif area. In addition to, the best procedure to be adopted on those environments should be including geometric attributes, and then modeling the residual anomaly. Furthermore, for purpose of oil and gas prospecting, our procedure is also effective, because it was able to not only detect the basin depocenter but also indicate the occurrence of possible unseen structural faults. Having said that, this procedure can be applied in any sedimentary basin regardless its type or location and it is strongly recommended, once there is several crustal models available.

\section{ACKNOWLEDGEMENTS}

The authors would like to thank the Programa de Recursos Humanos da Agência Nacional do Petróleo (portuguese version of National Petroleum Agency Resource Program - PRH/ANP) for providing all financial support that was extremely valuable for this research.

\section{REFERENCES}

ALLEN PA \& ALLEN JR. 2013. Basin analysis: principles and application to petroleum play assessment. John Wiley \& Sons. $642 \mathrm{pp}$.

ALMEIDA-FILHO R, ROSSETTI DF, MIRANDA FP, FERREIRA FJ, SILVA C \& BEISL C. 2009. Quaternary reactivation of a basement structure in the Barreirinhas basin, Brazilian Equatorial Margin. Quaternary Research, 72(1): 103-110.

ASSUMPÇÃO M, FENG M, TASSARA A \& JULIÀ J. 2013. Models of crustal thickness for South America from seismic refraction, receiver functions and surface wave tomography. Tectonophysics, 609: 82-96.

BAGHERBANDI M \& ESHAGH M. 2012. Crustal thickness recovery using an isostatic model and GOCE data. Earth, Planets and Space, 64(11): 1053-1057.

BARZAGHI R, REGUZZZONI M, BORGHI A, DE GAETANI C, SAMPIETRO D \& MAROTTA A. 2015. Global to local Moho estimate based on GOCE geopotential model and local gravity data. In: SNEEUW N, NOVÁK P, CRESPI M \& SANSÒ $F$ (Eds.). VIII Hotine-Marussi Symposium on Mathematical Geodesy. Springer. p. 275-282.

BELTRÃO J, SILVA J \& COSTA J. 1991. Robust polynomial fitting method for regional gravity estimation. Geophysics, 56(1): 80-89.

BELTRÃO JF. 1989. Uma nova abordagem para interpretação de anomalias gravimétricas regionais e residuais aplicada ao estudo da organização crustal: exemplo da Região Norte do Piauí e Noroeste do Ceará. Ph.D. thesis. Programa de Pós-Graduação em Geofísica. Universidade Federal do Pará. Brazil. 164 pp.

BLAKELY RJ. 1996. Potential theory in gravity and magnetic applications. Cambridge University Press. 464 pp.

BURKE K. 1976. Development of graben associated with the initial ruptures of the Atlantic Ocean. In: BOTT MHP (Ed.). Sedimentary Basins of Continental Margins and Cratons. Tectonophysics, 36(1-3): 93-112.

CPRM SGDB. 2014. CPRM - GEOBANK - Download de arquivos vetoriais. 
DE MATOS RMD. 2000. Tectonic evolution of the equatorial South Atlantic. Atlantic Rifts and Continental Margins, 115: 331-354.

DOLMAZ M, HISARLI Z, USTAÖMER T \& ORBAY N. 2005. Curie point depths based on spectrum analysis of aeromagnetic data, West Anatolian extensional province, Turkey. Pure and Applied Geophysics, 162(3): 571-590.

DREWES H, KUGLITSCH F, ADÁM J \& RÓZSA S. 2016. The Geodesist's Handbook 2016. Journal of Geodesy, 90(10): 907-1205.

DRINKWATER MR, HAAGMANS $R$, MUZI D, POPESCU A, FLOBERGHAGEN R, KERN M \& FEHRINGER M. 2006. The GOCE gravity mission: ESA's first core Earth explorer. In: Proceedings of the 3rd International GOCE User Workshop. p. 6-8. Frascati, Italy.

ESHAGH M, EBADI S \& TENZER R. 2017. Isostatic GOCE Moho model for Iran. Journal of Asian Earth Sciences, 138: 12-24.

ESHAGH M, HUSSAIN M, TENZER R \& ROMESHKANI M. 2016. Moho density contrast in central Eurasia from GOCE gravity gradients. Remote Sensing, 8(5): 418.

FEDI M \& QUARTA T. 1998. Wavelet analysis for the regional-residual and local separation of potential field anomalies. Geophysical Prospecting, 46(5): 507-525.

FElJÓ FJ. 1994. Bacia de Barreirinhas. Boletim de Geociências da Petrobras, 8(1): 103-109.

FLOBERGHAGEN $R$, FEHRINGER $M$, LAMARRE D, MUZI D, FROMMKNECHT B, STEIGER C, PIÑEIRO J \& DA COSTA A. 2011. Mission design, operation and exploitation of the gravity field and steady-state ocean circulation explorer mission. Journal of Geodesy, 85(11): 749-758.

GUPTA V \& RAMANI N. 1980. Some aspects of regional-residual separation of gravity anomalies in a Precambrian terrain. Geophysics, 45(9): 1412-1426.

GUSPI F \& INTROCASO B. 2000. A sparse spectrum technique for gridding and separating potential field anomalies. Geophysics, 65(4): 1154-1161.

JACOBSEN BH. 1987. A case for upward continuation as a standard separation filter for potential-field maps. Geophysics, 52(8): 1138-1148.

KEATING P \& PINET N. 2011. Use of non-linear filtering for the regional-residual separation of potential field data. Journal of Applied Geophysics, 73(4): 315-322.

KRUEGER A. 2012. The Brazilian Equatorial Margin from rift to drift: faulting, deposition, and deformation in the offshore Barreirinhas basin. Ph.D. thesis. University of Houston. 168 pp.

KRUEGER A, MURPHY M, GILBERT E \& BURKE K. 2012. Deposition and deformation in the deepwater sediment of the offshore Barreirinhas basin, Brazil. Geosphere, 8(6): 1606-1631.
LEFTWICH TE, VON FRESE RR, POTTS LV, KIM HR, ROMAN DR, TAYLOR PT \& BARTON M. 2005. Crustal modeling of the North Atlantic from spectrally correlated free-air and terrain gravity. Journal of Geodynamics, 40(1): 23-50.

MARTíN A, NÚÑEZ M, GILI J \& ANQUELA A. 2011. A comparison of robust polynomial fitting, global geopotential model and spectral analysis for regional-residual gravity field separation in the Doñana National Park (Spain). Journal of Applied Geophysics, 75(2): 327-337.

MARTÍNEZ-MORENO F, GALINDO-ZALDÍVAR J, PEDRERA A, TEIXIDÓ T, PEÑA J \& GONZÁLEZ-CASTILLO L. 2015. Regional and residual anomaly separation in microgravity maps for cave detection: the case study of Gruta de las Maravillas (SW Spain). Journal of Applied Geophysics, 114: 1-11.

MARTINS CM, BARBOSA VC \& SILVA JB. 2010. Simultaneous 3D depth-to-basement and density-contrast estimates using gravity data and depth control at few points. Geophysics, 75(3): I21-128.

MIGLIACCIO F, REGUZZONI M, SANSÒ F, TSCHERNING CC \& VEICHERTS M. 2010. GOCE data analysis: the space-wise approach and the first space-wise gravity field model. In: Proceedings of the ESA Living Planet Symposium. Bergen, Norway.

MILANI EJ, RANGEL HD, BUENO GV, STICA JM, WINTER WR, CAIXETA JM \& PESSOA NETO OC. 2007. Bacias sedimentares brasileiras: cartas estratigráficas. Mapa anexo ao Boletim de Geociências da Petrobras, 15(2): 573.

MONTESINOS F, CAMACHO A \& VIEIRA R. 1999. Analysis of gravimetric anomalies in Furnas Caldera (São Miguel, Azores). Journal of Volcanology and Geothermal Research, 92(1-2): 67-81.

NAGY D. 1966. The gravitational attraction of a right rectangular prism. Geophysics, 31(2): 362-371.

PAWLOWSKI RS. 1995. Preferential continuation for potential-field anomaly enhancement. Geophysics, 60(2): 390-398.

PAWLOWSKI RS \& HANSEN R. 1990. Gravity anomaly separation by Wiener filtering. Geophysics, 55(5): 539-548.

PLOUFF D. 1976. Gravity and magnetic fields of polygonal prisms and application to magnetic terrain corrections. Geophysics, 41(4): 727-741.

REBHAN H, AGUIRRE M \& JOHANNESSEN J. 2000. The gravity field and steady-state ocean circulation explorer mission-GOCE. ESA Earth Observation Quarterly, 66: 6-11.

REGUZZONI M \& SAMPIETRO D. 2015. GEMMA: An Earth crustal model based on GOCE satellite data. International Journal of Applied Earth Observation and Geoinformation, 35: 31-43.

RIDSDILL-SMITH TA. 1998. Separation filtering of aeromagnetic data using filter-banks. Exploration Geophysics, 29(3/4): 577-583. 
SAILHAC P \& GIBERT D. 2003. Identification of sources of potential fields with the continuous wavelet transform: two-dimensional wavelets and multipolar approximations. Journal of Geophysical Research: Solid Earth, 108(B5): 5003-5014.

SAMPIETRO D. 2016. Crustal modelling and Moho estimation with GOCE gravity data. In: FERNÁNDEZ-PRIETO D \& SABIA R (Eds.). Remote Sensing Advances for Earth System Science. p. 127-144, Springer.

SAMPIETRO D, REGUZZONI M \& NEGRETTI M. 2013. The GEMMA crustal model: first validation and data distribution. In: Proceedings of ESA Living Planet Symposium 2013. Edinburgh, UK, ESA SP-722, 8 pp.

SOARES JÚNIOR AV, COSTA JBS \& HASUI Y. 2008. Evolução da margem atlântica equatorial do Brasil: Três fases distensivas. Geociências (São Paulo), 27(4): 427-437.

SOARES JÚNIOR AV, HASUI Y, COSTA JBS \& MACHADO FB. 2011. Evolução do rifteamento e paleogeografia da margem Atlântica Equatorial do Brasil: Triássico ao Holoceno. Geociências, 30(4): 669-692.

SPECTOR A \& GRANT F. 1970. Statistical models for interpreting aeromagnetic data. Geophysics, 35(2): 293-302.

TELFORD WM, TELFORD W, GELDART L \& SHERIFF RE. 1990. Applied geophysics. Cambridge University Press. 792 pp.

TENZER R, GLADKIKH V, NOVÁK P \& VAJDA P. 2012. Spatial and spectral analysis of refined gravity data for modelling the crust-mantle interface and mantle-lithosphere structure. Surveys in Geophysics, 33(5): 817-839.

Recebido em 25 setembro, 2018 / Aceito em 27 novembro, 2018

Received on September 25, 2018 / Accepted on November 27, 2018
TROSDTORF JR I, ZALÁN P, FIGUEIREDO J \& SOARES E. 2007. Bacia de Barreirinhas. Boletim Geociências Petrobras, 15: 331-333.

UIEDA L \& BARBOSA VCF. 2016. Fast nonlinear gravity inversion in spherical coordinates with application to the South American Moho. Geophysical Journal International, 208(1): 162-176.

VAN DER MEIJDE M, JULIÀ J \& ASSUMPÇÃO M. 2013. Gravity derived Moho for South America. Tectonophysics, 609: 456-467.

VON FRESE RR, TAN L, WOO KIM J \& BENTLEY CR. 1999. Antarctic crustal modeling from the spectral correlation of free-air gravity anomalies with the terrain. Journal of Geophysical Research: Solid Earth, 104(B11): 25275-25296.

WATTS AB. 2001. Isostasy and Flexure of the Lithosphere. Cambridge University Press. 458 pp.

WOO KIM J, VON FRESE RR \& KIM HR. 2000. Crustal modeling from spectrally correlated free-air and terrain gravity data-a case study of Ohio. Geophysics, 65(4): 1057-1069.

XU Y, HAO T, LI Z, DUAN Q \& ZHANG L. 2009. Regional gravity anomaly separation using wavelet transform and spectrum analysis. Journal of Geophysics and Engineering, 6(3): 279-287.

YANG WC, SHI ZQ \& HOU ZZ. 2001. Discrete wavelet transform for multiple decomposition of gravity anomalies. Chinese Journal of Geophysics, 44(4): 529-537. 